\title{
Maternal overweight and obesity and risk of pre-eclampsia in women with type 1 diabetes or type 2 diabetes
}

\author{
Martina Persson $^{1,2}$ • Sven Cnattingius ${ }^{1}$ - Anna-Karin Wikström ${ }^{1,3} \cdot$ Stefan Johansson $^{1,2}$
}

Received: 15 April 2016 / Accepted: 9 June 2016 / Published online: 1 July 2016

(C) The Author(s) 2016. This article is published with open access at Springerlink.com

\begin{abstract}
Aims/hypothesis Women with type 1 or type 2 diabetes are at increased risk of pre-eclampsia. Overweight and obesity are associated with an increased risk of pre-eclampsia in women without diabetes. The aim of the study was to investigate the impact of maternal overweight and obesity on the risk of preeclampsia in women with type 1 diabetes or type 2 diabetes. Methods In a population-based cohort study including singleton births in Sweden, we estimated the risk of pre-eclampsia among women with type 1 diabetes $(n=7062)$ and type 2 diabetes $(n=886)$, and investigated whether maternal overweight (BMI $25-29.9 \mathrm{~kg} / \mathrm{m}^{2}$ ) and obesity (BMI $\geq 30.0 \mathrm{~kg} / \mathrm{m}^{2}$ ) modified the risk. Logistic regression analyses were used to estimate crude and adjusted ORs with $95 \%$ CIs, using women without diabetes as the reference group $(n=1,509,525)$.

Results Compared with women without diabetes, the adjusted ORs for pre-eclampsia in women with type 1 and type 2 diabetes were $5.74(95 \%$ CI $5.31,6.20)$ and $2.11(95 \%$ CI 1.65, 2.70), respectively. The corresponding risks of pre-eclampsia combined with preterm birth were even higher. Risks of pre-eclampsia increased with maternal overweight (BMI 25-29.9 kg/m ${ }^{2}$ ) and obesity (BMI $\geq 30.0 \mathrm{~kg} / \mathrm{m}^{2}$ ), foremost in women without
\end{abstract}

Martina Persson

Martina.Persson@ki.se

1 Clinical Epidemiology Unit, Department of Medicine Solna, Karolinska Institutet, Eugeniahemmet T2,

17176 Stockholm, Sweden

2 Department of Clinical Science and Education, Södersjukhuset, Karolinska Institutet, Stockholm, Sweden

3 Department of Women's and Children's Health, Uppsala University, Uppsala, Sweden diabetes, to a lesser extent in women with type 1 diabetes but not in women with type 2 diabetes.

Conclusions/interpretation Maternal overweight and obesity increased risks of pre-eclampsia in women with type 1 diabetes but not in women with type 2 diabetes. Even so, considering associations between maternal BMI and overall maternal and offspring risk, all women (with and without diabetes) should aim for a normal weight before pregnancy.

Keywords BMI - Diabetes type 1 -Diabetes type $2 \cdot$ Moderate pre-eclampsia $\cdot$ Obesity $\cdot$ Overweight $\cdot$ Pre-eclampsia $\cdot$ Risk of pre-eclampsia $\cdot$ Severe pre-eclampsia

\section{Abbreviation \\ MBR Medical Birth Register}

\section{Introduction}

The outcome of pregnancies complicated by pregestational diabetes has markedly improved over the last few decades. However, the risk of severe maternal complications is still considerably increased $[1,2]$, including a 2-6 times higher risk of pre-eclampsia compared with women without diabetes [3]. Pre-eclampsia accounts for more than half of all maternal deaths per year in high income countries [4], and is associated with substantially increased risks of stillbirth, preterm birth and infant mortality [5, 6]. Effective predictors for its early detection are lacking [7] and delivery is the only cure for preeclampsia.

In women with type 1 diabetes, a number of risk factors for pre-eclampsia have been identified [8]. The most salient include elevated first trimester $\mathrm{HbA}_{1 \mathrm{c}}$ and both incipient and overt nephropathy $[9,10]$. Risk factors for pre-eclampsia in 
women with type 2 diabetes are less well studied [11]. However, the prevalence of overweight and obesity continues to rise in general [12], also in women with type 1 or type 2 diabetes $[13,14]$.

In women without diabetes, high BMI is an important risk factor for both moderate and severe pre-eclampsia $[15,16]$. We previously demonstrated that maternal overweight and obesity increase the risk of pre-eclampsia in women with type 1 diabetes [17]. However, we are unaware of studies focusing on associations between maternal overweight and obesity and the risk of pre-eclampsia in women with type 2 diabetes. Therefore, the aim of the current study was to compare the impact of maternal BMI on pre-eclampsia risks in women with type 1 and type 2 diabetes. We also wanted to explore the effect of maternal overweight and obesity on risks of preeclampsia subtypes, including moderate and severe preeclampsia, and pre-eclampsia leading to preterm birth.

\section{Methods}

Study design and study population The national Swedish Medical Birth Register (MBR) contains data on more than 98\% of all births in Sweden. Between 1997 and 2012, the MBR added information on 1,600,575 births. We excluded mothers with missing personal identification numbers $(n=19,001)$ and with no information on country of birth $(n=1108)$. We also excluded multiple births $(n=46,662)$ and births with unknown gestational age $(n=1122)$. In order to compare the risks of pre-eclampsia in women with type 1 and type 2 diabetes and women without diabetes, we also excluded women with gestational diabetes $(n=15,209)$. Thus, the final study population comprised 1,517,473 women with singleton births.

The Swedish MBR is subject to quality control by the National Board of Health and Welfare, and the coverage and validity of most variables are considered to be high [18]. Information on maternal sociodemographic factors, anthropometry, medical history, and obstetric and perinatal outcome is recorded prospectively by midwifes and physicians using standardised forms during pregnancy, delivery and the neonatal period. Maternal and neonatal diagnoses are classified by the physician according the International Classification of Diseases; ICD-10 has been used since 1997. We used the personal identification number [19] assigned to all citizens in Sweden to cross-link data from the MBR to the Total Population Register for the maternal country of birth and to the Education Register for the mother's highest attained level of education [20, 21]. Ethical approval was obtained from the Research Ethics Committee of the Karolinska Institutet, Stockholm, Sweden (no. 2012/1813-31/4).
Exposures The main exposures were maternal type 1 and type 2 diabetes, and maternal BMI. Identification of women with type 1 or type 2 diabetes was based on ICD-10 codes $\mathrm{O} 240$ and $\mathrm{O} 241$, respectively. The reference group comprised women without gestational diabetes or type 1 or type 2 diabetes. Maternal BMI $\left(\mathrm{kg} / \mathrm{m}^{2}\right)$ was calculated from weight measured wearing light indoor clothing and selfreported height at the first antenatal visit, usually during the first trimester [18]. Women were categorised according to the WHO criteria as underweight (BMI $<18.5 \mathrm{~kg} / \mathrm{m}^{2}$ ), normal weight (BMI 18.5-24.9 $\mathrm{kg} / \mathrm{m}^{2}$ ), overweight (BMI $25-29.9 \mathrm{~kg} / \mathrm{m}^{2}$ ) or obese (BMI $\geq 30 \mathrm{~kg} / \mathrm{m}^{2}$ ) [22].

Covariates Information on maternal height, age at delivery, parity and self-reported smoking, as recorded at the first antenatal visit, was retrieved from the MBR. Covariates were categorised as shown in Table 1.

Outcomes The main outcome was pre-eclampsia, based on ICD-10 codes (O140, O141, O149 and O15). Pre-eclampsia was further divided into mild to moderate (ICD-10 codes O140 and O149, respectively) and severe (ICD-10 codes O141 and O15). Pre-eclampsia was also stratified by gestational age at delivery into preterm and term pre-eclampsia, defined as a recorded pre-eclampsia diagnosis combined with preterm or term delivery (at $<37$ weeks or $\geq 37$ weeks, respectively). There are several definitions of pre-eclampsia, and classification may therefore vary between countries. In Sweden, the clinical definition of pre-eclampsia was BP $\geq 140 / 90 \mathrm{mmHg}$ (systolic/diastolic) combined with proteinuria (at least $0.3 \mathrm{~g}$ per $24 \mathrm{~h}$ or a score of $\geq 1$ on a urine dipstick on at least two subsequent occasions) during the study period. Severe pre-eclampsia is commonly defined as pre-eclampsia with a systolic $\mathrm{BP} \geq 160 \mathrm{mmHg}$, and/or a diastolic BP $\geq 110 \mathrm{mmHg}$ and/or multiorgan involvement [23]. A Swedish validation study found good agreement between registry information on pre-eclampsia diagnoses and information in the individual records when using ICD-9 codes [24], and a Danish study showed good validity for registry information on pre-eclampsia when using ICD-10 codes [25].

Statistical analyses Rates of pre-eclampsia were calculated separately for women without diabetes, women with type 1 diabetes and women with type 2 diabetes. We used logistic regression analyses to estimate ORs and 95\% CIs for preeclampsia and subgroups of pre-eclampsia in women with type 1 or type 2 diabetes. Women without diabetes were used as the reference population. In the first adjusted model, ORs were only adjusted for maternal BMI (model 1), while in the second model ORs were additionally adjusted for maternal parity, age, height, smoking, maternal country of birth and education (model 2). To investigate whether the effect of BMI on pre-eclampsia risk differed in women with and 
Table 1 Maternal characteristics and rates of pre-eclampsia in women with singleton births in Sweden between 1997 and 2012

\begin{tabular}{|c|c|c|c|}
\hline \multirow[t]{2}{*}{ Maternal characteristics } & \multirow[t]{2}{*}{ Total $(n)$} & \multicolumn{2}{|c|}{ Pre-eclampsia } \\
\hline & & $n$ & $\%$ \\
\hline Total & $1,517,473$ & 43,223 & 2.8 \\
\hline \multicolumn{4}{|l|}{ Maternal age (years) } \\
\hline$\leq 24$ & 227,953 & 7602 & 3.3 \\
\hline $25-29$ & 469,675 & 13,521 & 2.9 \\
\hline $30-34$ & 523,845 & 13,448 & 2.6 \\
\hline$\geq 35$ & 296,000 & 8652 & 2.9 \\
\hline \multicolumn{4}{|l|}{ Parity } \\
\hline Nulliparous & 671,893 & 28,966 & 4.3 \\
\hline Parous & 845,580 & 14,257 & 1.7 \\
\hline \multicolumn{4}{|c|}{ Early pregnancy BMI $\left(\mathrm{kg} / \mathrm{m}^{2}\right)$} \\
\hline$<18.5$ & 32,095 & 538 & 1.7 \\
\hline $18.5-24.9$ & 830,141 & 17,661 & 2.1 \\
\hline $25.0-29.9$ & 338,897 & 11,340 & 3.4 \\
\hline $30.0-34.9$ & 106,178 & 5533 & 5.2 \\
\hline$\geq 35.0$ & 42,046 & 3213 & 7.6 \\
\hline Data missing & 168,116 & 4938 & 2.9 \\
\hline \multicolumn{4}{|l|}{ Maternal height (cm) } \\
\hline$<155$ & 45,395 & 1429 & 3.2 \\
\hline $155-164$ & 499,906 & 15,094 & 3.0 \\
\hline $165-174$ & 737,640 & 20,348 & 2.8 \\
\hline$\geq 175$ & 142,284 & 3585 & 2.5 \\
\hline Data missing & 92,248 & 2767 & 3.0 \\
\hline \multicolumn{4}{|c|}{ Daily smoking in early pregnancy } \\
\hline No & $1,308,648$ & 38,040 & 2.9 \\
\hline Yes & 128,841 & 2714 & 2.1 \\
\hline Data missing & 79,984 & 2469 & 3.1 \\
\hline \multicolumn{4}{|l|}{ Education (years) } \\
\hline 9 & 376,896 & 10,714 & 2.8 \\
\hline $10-11$ & 394,385 & 12,604 & 3.2 \\
\hline 12 & 210,515 & 5934 & 2.8 \\
\hline$\geq 13$ & 518,037 & 13,566 & 2.6 \\
\hline Data missing & 17,640 & 405 & 2.3 \\
\hline \multicolumn{4}{|l|}{ Mother's country of birth } \\
\hline Nordic & $1,243,543$ & 37,592 & 3.0 \\
\hline Non-Nordic & 273,930 & 5631 & 2.0 \\
\hline
\end{tabular}

without diabetes, we decided a priori to perform stratified analyses of associations between BMI and pre-eclampsia risk in women without diabetes, women with type 1 diabetes and women with type 2 diabetes. Interactions were tested separately for women with type 1 and type 2 diabetes. Interaction terms were introduced in the multivariate model (model 2), and a $p$ value of $<0.05$ for the interaction term was considered statistically significant. For women with type 1 diabetes, analyses were stratified by BMI category for all subtypes of preeclampsia. Due to power concerns, it was not possible to perform these analyses for women with type 2 diabetes. In all analyses, the general estimation equation model was applied to account for repeated pregnancies.

\section{Results}

Rates of pre-eclampsia were higher in younger ( $\leq 24$ years) and nulliparous women, and increased with maternal BMI (Table 1). A lower pre-eclampsia rate was observed in smokers compared with non-smokers. Further, the rate of pre-eclampsia was higher in Nordic women than in nonNordic women.

Compared with women without diabetes, the crude OR for pre-eclampsia was more than six times higher in women with type 1 diabetes and 3.5 times higher in women with type 2 diabetes. These risk estimates were reduced after adjustment for maternal BMI, especially for women with type 2 diabetes (Table 2, model 1). Further adjustment for other covariates only slightly changed these risks (Table 2 , model 2 ).

Type 1 and type 2 diabetes were both associated with increased ORs for all subgroups of pre-eclampsia, and type 1 diabetes was consistently associated with higher risks compared with type 2 diabetes (Table 3). Compared with women without diabetes, the adjusted OR for severe pre-eclampsia was almost six times higher in women with type 1 diabetes and approximately 2.5 times higher in women with type 2 diabetes. The highest ORs were observed for pre-eclampsia related to preterm birth. Compared with women without diabetes, the crude and adjusted ORs of pre-eclampsia with preterm birth were close to 11 times and nine times higher for women with type 1 diabetes. In women with type 2 diabetes, the OR for pre-eclampsia leading to preterm birth was reduced from 4.74 (95\% CI 3.13, 7.16) to $3.11(95 \%$ CI $2.05,4.70)$ after adjustment for BMI (Table 3).

Data on BMI was available for $88.3 \%$ of women with type 1 diabetes, $90.6 \%$ of women with type 2 diabetes and $88.9 \%$ of women in the reference population. In all, $0.4 \%$ of women with type 1 diabetes were underweight, $47.9 \%$ were normal weight, $33.6 \%$ were overweight and $18 \%$ were obese. Corresponding figures for women with type 2 diabetes were: underweight, $0.5 \%$; normal weight, $16.9 \%$; overweight, $27.7 \%$; and obese, $54.7 \%$. There were significant interactions between maternal BMI and diabetes status with regard to preeclampsia risk for both type $1(p<0.001)$ and type $2(p=0.01)$ diabetes. We therefore performed stratified analyses of associations between maternal BMI and pre-eclampsia in women without diabetes, with type 1 diabetes, and with type 2 diabetes. Especially in women without diabetes, but also in women with type 1 diabetes, rates of pre-eclampsia increased with maternal overweight and obesity (Table 4 ). The highest overall pre-eclampsia rate $(18.6 \%)$ was seen in obese women with type 1 diabetes. For those without diabetes, overweight and 
Table 2 Type 1 and type 2 diabetes and risks of pre-eclampsia

\begin{tabular}{lllllll}
\hline Diabetic disease & Total $(n)$ & \multicolumn{2}{l}{ Pre-eclampsia } & & \\
\cline { 3 - 7 } & & $n$ & $\%$ & Crude OR $(95 \%$ CI $)$ & \multicolumn{2}{l}{ Adjusted OR (95\% CI) } \\
\cline { 3 - 7 } & & & & & Model 1 & Model 2 $^{\mathrm{b}}$ \\
\hline No & $1,509,525$ & 42,034 & 2.8 & 1.00 & 1.00 & 1.00 \\
Type 1 & 7062 & 1103 & 15.6 & $6.32(5.88,6.78)$ & $5.74(5.31,6.20)$ & $5.64(5.19,6.12)$ \\
Type 2 & 886 & 86 & 9.7 & $3.45(2.71,4.39)$ & $2.11(1.65,2.70)$ & $2.30(1.67,3.17)$
\end{tabular}

${ }^{\text {a }}$ Adjusted for maternal BMI

${ }^{\mathrm{b}}$ Adjusted for maternal BMI, height, age, parity, education, smoking and country of birth. obese women had 1.7-fold and a more than threefold increased odds of pre-eclampsia, respectively, compared with normal weight women (Table 4). In women with type 2 diabetes, overweight and obesity were not associated with increased risks of pre-eclampsia compared with normal weight.

Compared with normal weight women with type 1 diabetes, obesity led to modest increments in the risk of all subtypes of pre-eclampsia: the adjusted ORs for moderate pre-eclampsia, severe pre-eclampsia and pre-eclampsia with preterm birth in obese women with type 1 diabetes were 1.42 (95\% CI 1.11, 1.82), 1.49 (95\% CI 1.09, 2.05) and 1.33 (95\% CI 0.97, 1.83), respectively.

\section{Discussion}

To our knowledge, the present population-based cohort study is the first to demonstrate the impact of maternal BMI in women with type 1 and type 2 diabetes on the risk of pre-eclampsia, including subtypes of pre-eclampsia. We found no evidence that maternal overweight and obesity are associated with an increased risk of pre-eclampsia in women with type 2 diabetes, as opposed to women with type 1 diabetes and, especially, women without diabetes. The observation that rates of preeclampsia were increased in women with type 1 and type 2 diabetes is in accordance with previous reports. However, we also found consistently higher rates of all subtypes of preeclampsia in women with type 1 diabetes compared with women with type 2 diabetes. Rates of pre-eclampsia were also significantly higher in Nordic than in non-Nordic women. This is consistent with previous findings [26, 27].

Compared with women without diabetes, the ORs for preeclampsia and subtypes of pre-eclampsia were substantially increased in women with type 1 diabetes, and risk estimates were only slightly attenuated after adjustment for BMI. This demonstrates that the association between type 1 diabetes and

Table 3 Type 1 and type 2 diabetes and risks of pre-eclampsia subtypes

\begin{tabular}{|c|c|c|c|c|c|c|c|}
\hline \multirow[t]{3}{*}{ Pre-eclampsia subtype } & \multirow[t]{3}{*}{ Diabetic disease } & \multirow[t]{3}{*}{ Total $(n)$} & \multicolumn{5}{|c|}{ Pre-eclampsia } \\
\hline & & & \multirow[t]{2}{*}{$n$} & \multirow[t]{2}{*}{$\%$} & \multirow[t]{2}{*}{ Crude OR $(95 \% \mathrm{CI})$} & \multicolumn{2}{|c|}{ Adjusted OR $(95 \% \mathrm{CI})$} \\
\hline & & & & & & Model $1^{\text {a }}$ & Model $2^{\mathrm{b}}$ \\
\hline \multirow[t]{3}{*}{ Mild/moderate } & No & $1,509,525$ & 28,460 & 1.9 & 1.00 & 1.00 & 1.00 \\
\hline & Type 1 & 7062 & 704 & 10.0 & $5.69(5.24,6.19)$ & $5.08(4.65,5.56)$ & $4.89(4.45,5.38)$ \\
\hline & Type 2 & 886 & 58 & 6.5 & $3.44(2.58,4.58)$ & $2.01(1.50,2.68)$ & $2.18(1.50,3.16)$ \\
\hline \multirow[t]{3}{*}{ Severe } & No & $1,509,525$ & 13,574 & 0.9 & 1.00 & 1.00 & 1.00 \\
\hline & Type 1 & 7062 & 399 & 5.6 & $6.51(5.84,7.25)$ & $5.95(5.29,6.69)$ & $5.75(5.08,6.52)$ \\
\hline & Type 2 & 886 & 28 & 3.2 & $3.50(2.37,5.16)$ & $2.29(1.53,3.45)$ & $2.45(1.47,4.07)$ \\
\hline \multirow[t]{3}{*}{ Preterm (<37 weeks) } & No & $1,509,525$ & 9360 & 0.6 & 1.00 & 1.00 & 1.00 \\
\hline & Type 1 & 7062 & 435 & 6.2 & $10.35(9.29,11.52)$ & $9.08(8.06,10.22)$ & $8.72(7.68,9.89)$ \\
\hline & Type 2 & 886 & 27 & 3.1 & $4.74(3.13,7.16)$ & $3.11(2.05,4.70)$ & $3.22(1.93,5.37)$ \\
\hline \multirow[t]{3}{*}{ Term ( $\geq 37$ weeks) } & No & $1,509,525$ & 32,674 & 2.2 & 1.00 & 1.00 & 1.00 \\
\hline & Type 1 & 7062 & 668 & 9.5 & $4.65(4.27,5.06)$ & $4.30(3.93,4.71)$ & $4.19(3.81,4.62)$ \\
\hline & Type 2 & 886 & 59 & 6.7 & $3.06(2.32,4.03)$ & $1.80(1.36,2.40)$ & $1.96(1.36,2.82)$ \\
\hline
\end{tabular}

${ }^{a}$ Adjusted for maternal BMI $\left(\mathrm{kg} / \mathrm{m}^{2}\right)$

${ }^{\mathrm{b}}$ Adjusted for maternal BMI, height, age, parity, education, smoking and country of birth 
Table 4 Risks of pre-eclampsia stratified by maternal BMI in women with and without diabetes

\begin{tabular}{|c|c|c|c|c|c|c|}
\hline \multirow[t]{3}{*}{ Diabetic disease } & \multicolumn{6}{|c|}{ BMI $\left(\mathrm{kg} / \mathrm{m}^{2}\right)$} \\
\hline & \multicolumn{2}{|c|}{$18.5-24.9$} & \multicolumn{2}{|c|}{$25-29.9$} & \multicolumn{2}{|l|}{$\geq 30$} \\
\hline & $\%$ & OR $(95 \% \mathrm{CI})^{\mathrm{a}}$ & $\%$ & OR $(95 \% \mathrm{CI})^{\mathrm{a}}$ & $\%$ & OR $(95 \% \text { CI })^{a}$ \\
\hline No & 2.1 & 1.00 & 3.3 & $1.69(1.64,1.73)$ & 5.8 & $3.22(3.12,3.32)$ \\
\hline Type 1 & 14.2 & 1.00 & 16.1 & $1.17(0.99,1.38)$ & 18.6 & $1.48(1.20,1.82)$ \\
\hline Type 2 & 8.8 & 1.00 & 6.9 & $0.84(0.33,2.16)$ & 11.5 & $1.23(0.56,2.72)$ \\
\hline
\end{tabular}

${ }^{a}$ Underweight women were excluded

${ }^{\mathrm{b}}$ Adjusted for maternal BMI, height, age, parity, education, smoking and country of birth pre-eclampsia is independent of BMI, even though the odds for pre-eclampsia increased further with maternal overweight and obesity. In contrast, in women with type 2 diabetes, the risk of pre-eclampsia was partially confounded by BMI, while increasing maternal BMI did not further increase the preeclampsia risk. These discrepancies probably reflect differences in genetic factors and the clinical expression of both type 1 and type 2 diabetes. In addition, the impact of BMI on the risk of pre-eclampsia may vary with the duration of diabetes, and the presence or absence of diabetes-related complications and other risk factors for pre-eclampsia. The lack of effect of BMI on the risk of pre-eclampsia in women with type 2 diabetes and the modestly increment in pre-eclampsia risk conveyed by maternal obesity in women with type 1 diabetes demonstrate that diabetes disease per se is a much stronger risk factor for pre-eclampsia than BMI. This is also consistent with comparable risks of cardiovascular death for normal weight and overweight/obese adults with type 2 diabetes [28]. However, the vast majority (83\%) of women with type 2 diabetes in our study were either overweight or obese (BMI $\geq 25 \mathrm{~kg} / \mathrm{m}^{2}$ ), and considerably fewer women with type 2 diabetes than with type 1 diabetes. Thus, it is possible that the range of exposures was insufficient to demonstrate a significant contribution of BMI on the risk of pre-eclampsia in women with type 2 diabetes or that a larger cohort was needed to demonstrate an effect.

Studies comparing rates of pre-eclampsia in women with type 1 diabetes and type 2 diabetes are scarce, and contradictory results have been reported [29, 30]. In the present study, rates of pre-eclampsia and subtypes of pre-eclampsia were significantly higher in women with type 1 diabetes than in women with type 2 diabetes. Differences in the rates of preeclampsia in women with type 1 diabetes or type 2 diabetes may be attributable to differences in risk factors, such as chronic hypertension, level of glycaemic control, duration of diabetes disease and diabetes microangiopathy. In addition, comparison of placental findings in women with type 1 or type 2 diabetes suggest that the strain of pregnancy may affect maternal vascularisation differently in these two groups [31].

Diabetic nephropathy is a complication of around $2.5-5 \%$ of pregnancies in women with diabetes $[32,33]$ and is a strong risk factor for pre-eclampsia [34]. Interestingly, in women with type 1 diabetes and nephropathy, maternal overweight was the only additional factor associated with adverse pregnancy outcome, whereas duration of diabetes, level of glycaemic control and weight gain in pregnancy did not influence risks [35]. Microalbuminuria, the forerunner to diabetic nephropathy has also been associated with a fourfold increased risk of pre-eclampsia in women with type 1 diabetes [36]. There has been less investigation into the impact of different degrees of nephropathy on the risk of pre-eclampsia in women with type 2 diabetes. However, a recent nationwide study from Denmark demonstrated that women with type 2 diabetes and overt nephropathy or microalbuminuria had comparable rates of pre-eclampsia to those of women with type 1 diabetes and different degrees of diabetic nephropathy [32]. Elevated $\mathrm{HbA}_{1 \mathrm{c}}$ in early pregnancy is another important risk factor for pre-eclampsia in women with type 1 diabetes $[9$, 37]. Obesity is associated with increased insulin resistance and elevated glucose concentrations [38]. Against this background, one might speculate that the increment in risk of preeclampsia in obese women with type 1 diabetes may reflect a poorer glycaemic control compared with normal weight women with type 1 diabetes. Furthermore, the aetiology of preeclampsia remains undefined. Pre-eclampsia includes abnormal vascular development of the placenta and systemic maternal endothelial dysfunction [3]. Obesity and pre-eclampsia share several features, including subclinical inflammation, insulin resistance and lipotoxicity $[39,40]$. Lipotoxicity is associated with maternal vascular dysfunction and reduced trophoblast invasion into the developing placenta; it has been proposed to link maternal overweight and obesity to the risk of pre-eclampsia [39]. It has also been hypothesised that maternal obesity may increase the risk of pre-eclampsia by reducing endogenous production of nitric oxide, with the subsequent increased risk of endothelial dysfunction [41]. Adverse metabolic and vascular effects of overweight and obesity are particularly seen in visceral obesity. Thus, it is possible that the impact of maternal BMI on the risk of pre-eclampsia may differ between women with different fat mass distributions.

Strengths of this study include the population-based design, including data on all pregnancies in women with type 
1 diabetes and type 2 diabetes in Sweden between 1997 and 2012. Data were prospectively collected within a healthcare context, which largely excludes recall bias. The large study cohort enabled us to investigate risks of pre-eclampsia and subtypes of pre-eclampsia in women with type 1 diabetes and type 2 diabetes, and also to investigate the importance of BMI in stratified analyses. In Sweden, management of pregnancies with pregestational diabetes is uniform and pregnancy outcomes do not differ with geographical area [1]. We were able to adjust for important maternal diagnoses and confounders $[18,24,25]$. During the study period, the main screening strategy for identifying gestational diabetes was repeated capillary random plasma glucose values of $\geq 9 \mathrm{mmol} / 1$ or the presence of traditional risk factors (i.e. first-degree family history of diabetes, obesity, history of gestational diabetes or delivery of a large-for-date baby in a previous pregnancy). Plasma glucose is also measured in cases of glucosuria. In addition, an OGTT is usually also performed in cases of fetal growth acceleration or polyhydramnios. A diagnosis of gestational diabetes was based on an OGTT (75 g glucose) performed within a week for cases in which a random plasma glucose value was above the limit. Women with traditional risk factors are tested once or twice during the first 30 weeks of gestation. A diagnosis of gestational diabetes mellitus was based on a fasting plasma glucose value of $\geq 7 \mathrm{mmol} / \mathrm{l}$ and/or a $2 \mathrm{~h}$ plasma glucose value of $\geq 10 \mathrm{mmol} / \mathrm{l}$. As almost all obese women (BMI $\geq 30 \mathrm{~kg} / \mathrm{m}^{2}$ ) are submitted to an OGTT during antenatal care, it is unlikely that gestational diabetes was undetected in this group of women.

While we consider the risk of misclassification of type 1 diabetes to be negligible, we cannot exclude the possibility that some misclassification of type 2 diabetes and gestational diabetes may have biased our results: women with type 2 diabetes may have been misclassified as having gestational diabetes.

The Swedish MBR does not contain information on maternal glycaemic control, duration of diabetes or diabetes-associated complications. In this study, we used BMI in early pregnancy as a proxy for fat mass. The validity of this proxy measure is supported by the strong association $\left(r^{2}=0.84\right)$ between BMI and total fat mass in early pregnancy [42]. However, it is important to remember that the impact of maternal BMI on the risk of preeclampsia may differ with distribution of fat mass.

In conclusion, we found that maternal overweight and obesity increase the risks of pre-eclampsia and subtypes of preeclampsia in women with type 1 diabetes and, especially, in women without diabetes. In contrast, maternal BMI did not substantially influence the risk of pre-eclampsia in women with type 2 diabetes. Our findings indicate that striving for a normal pre-pregnancy BMI could reduce the risk of preeclampsia in women with type 1 diabetes and women without diabetes. Further, as maternal BMI is also related to other pregnancy and obstetric complications, women with type 2 diabetes would probably benefit in other respects from having a normal weight. Given the increasing prevalence of maternal obesity and the severity of the preeclamptic disease, it is important that our results are confirmed in other populations.

Funding The study was supported by the Swedish Research Council for Health, Working Life and Welfare (grant no. 20140-073; SC), the Swedish Research Council (grant no. 20143-561; A-KW) and the Karolinska Institutet (distinguished professor award to SC). MP was supported by Stockholm City Council (clinical postdoctoral position).

Duality of interest statement The authors declare that there is no duality of interest associated with this manuscript.

Contribution statement All authors conceived the research; SC acquired the data; MP and SJ analysed the data; all authors interpreted the results; MP drafted the manuscript; and SC, A-KW, SJ critically revised the manuscript. All authors gave final approval of the version to be published. SJ is the guarantor of this study.

Open Access This article is distributed under the terms of the Creative Commons Attribution 4.0 International License (http:// creativecommons.org/licenses/by/4.0/), which permits unrestricted use, distribution, and reproduction in any medium, provided you give appropriate credit to the original author(s) and the source, provide a link to the Creative Commons license, and indicate if changes were made.

\section{References}

1. Persson M, Norman M, Hanson U (2009) Obstetric and perinatal outcomes in type 1 diabetic pregnancies: a large, population-based study. Diabetes Care 32:2005-2009

2. Murphy HR, Steel SA, Roland JM et al (2011) Obstetric and perinatal outcomes in pregnancies complicated by type 1 and type 2 diabetes: influences of glycaemic control, obesity and social disadvantage. Diabetic Medi: J Br Diabetic Assoc 28:1060-1067

3. Weissgerber TL, Mudd LM (2015) Preeclampsia and diabetes. Curr Diab Rep 15:9

4. Spradley FT, Palei AC, Granger JP (2015) Increased risk for the development of preeclampsia in obese pregnancies: weighing in on the mechanisms. Am J Physiol Regul Integr Comp Physiol 309: R1326-R1343

5. Goldenberg RL, Culhane J, Iams JD, Romero R (2008) Epidemiology and causes of preterm birth. Lancet (London, England) 371:75-84

6. Xiong X, Buekens P, Pridjian G, Fraser WD (2007) Pregnancyinduced hypertension and perinatal mortality. J Reprod Med 52: 402-406

7. Wotherspoon AC, Young IS, McCance DR, Holmes VA (2016) Evaluation of biomarkers for the prediction of pre-eclampsia in women with type 1 diabetes mellitus: A systematic review. J Diabetes Complications. doi:10.1016/j.jdiacomp.2016.02.001

8. Duckitt K, Harrington D (2005) Risk factors for pre-eclampsia at antental booking: systemic review of controlled studies. Br Med J (Clin Res Ed) 330:549-550

9. Hanson U, Persson B (1998) Epidemiology of pregnancy-induced hypertension and preeclampsia in type 1 (insulin-dependent) diabetic pregnancies in Sweden. Acta Obstet Gynecol Scand 77:620 624 
10. Klemetti MM, Laivuori H, Tikkanen M, Nuutila M, Hiilesmaa V, Teramo K (2015) White's classification and pregnancy outcome in women with type 1 diabetes: a population-based cohort study. Diabetologia 59:92-100

11. Gordin D, Forsblom C, Groop PH, Teramo K, Kaaja R (2014) Risk factors of hypertensive pregnancies in women with diabetes and the influence on their future life. Ann Med 46:498-502

12. Ogden CL, Carroll MD, Fryar CD, Flegal KM (2015) Prevalence of obesity among adults and youth: United States, 2011-2014. NCHS Data Brief 2015 Nov. 1-8

13. Klemetti M, Nuutila M, Tikkanen M, Kari MA, Hiilesmaa V, Teramo K (2012) Trends in maternal BMI, glycaemic control and perinatal outcome among type 1 diabetic pregnant women in 1989 2008. Diabetologia 55:2327-2334

14. Owens LA, Egan AM, Carmody L, Dunne F (2016) Ten years of optimizing outcomes for women with type 1 and type 2 diabetes in pregnancy - the Atlantic DIP experience. J Clin Endocrinol Metab 101:1598-1605

15. Hyperglycemia and Adverse Pregnancy Outcome (HAPO) Study Cooperative Research Group (2010) Hyperglycemia and Adverse Pregnancy Outcome (HAPO) study: preeclampsia. Am J Obstet Gynecol 202(255):e251-e257

16. Sohlberg S, Stephansson O, Cnattingius S, Wikstrom AK (2012) Maternal body mass index, height, and risks of preeclampsia. Am J Hypertens 25:120-125

17. Persson M, Pasupathy D, Hanson U, Westgren M, Norman M (2012) Pre-pregnancy body mass index and the risk of adverse outcome in type 1 diabetic pregnancies: a population-based cohort study. BMJ Open 2:e000601

18. National Board of Health and Welfare (Socialstyrelsen) (2003) NBoHaW Swedish Medical Birth Register. A summary of content and quality. 2003-112-3. Available from www.socialstyrelsense/publikationer 2003/2003-112-3, accessed 15 June 2016

19. Ludvigsson JF, Otterblad-Olausson P, Pettersson BU, Ekbom A (2009) The Swedish personal identity number: possibilities and pitfalls in healthcare and medical research. Eur J Epidemiol 24: 659-667

20. Ludvigsson JF, Almqvist C, Bonamy AE et al (2016) Registers of the Swedish total population and their use in medical research. Eur J Epidemiol 31:125-136

21. Statistics Sweden (2015) Utvärdering av Utbildningsregistret [Evaluation of the Swedish Register of Education]. Accessed 21 May 2015 [in Swedish]

22. WHO (2015) Global database on body mass index. http://apps.who. int/bmi, accessed 20 May 2016

23. Sibai BM (2003) Diagnosis and management of gestational hypertension and preeclampsia. Obstet Gynecol 102:181-192

24. Ros HS, Cnattingius S, Lipworth L (1998) Comparison of risk factors for preeclampsia and gestational hypertension in a population-based cohort study. Am J Epidemiol 147:10621070

25. Klemmensen AK, Olsen SF, Osterdal ML, Tabor A (2007) Validity of preeclampsia-related diagnoses recorded in a national hospital registry and in a postpartum interview of the women. Am J Epidemiol 166:117-124
26. Fadl HEOI, Hanson US (2012) Outcomes of gestational diabetes in Sweden depending on country of birth. Acta Obstet Gynecol Scand 91:1326-1330

27. Perni UC, Wikström A, Cnattingius S, Villamr E (2012) Interpregnancy change in smoking habits and risk of preeclampsia: a population-based study. Am J Hypertens 25:372-378

28. Carnethon MR, De Chavez PJ, Biggs ML et al (2012) Association of weight status with mortality in adults with incident diabetes. JAMA 308:581-590

29. Cundy T, Slee F, Gamble G, Neale L (2002) Hypertensive disorders of pregnancy in women with Type 1 and Type 2 diabetes. Diabet Med: J Br Diabet Assoc 19:482-489

30. Balsells M, Garcia-Patterson A, Gich I, Corcoy R (2009) Maternal and fetal outcome in women with type 2 versus type 1 diabetes mellitus: a systematic review and metaanalysis. J Clin Endocrinol Metab 94:4284-4291

31. Starikov R, Inman K, Chen K et al (2014) Comparison of placental findings in type 1 and type 2 diabetic pregnancies. Placenta 35: 1001-1006

32. Damm JA, Asbjornsdottir B, Callesen NF et al (2013) Diabetic nephropathy and microalbuminuria in pregnant women with type 1 and type 2 diabetes: prevalence, antihypertensive strategy, and pregnancy outcome. Diabetes Care 36:3489-3494

33. Landon MB (2007) Diabetic nephropathy and pregnancy. Clin Obstet Gynecol 50:998-1006

34. Klemetti MM, Laivuori H, Tikkanen M, Nuutila M, Hiilesmaa V, Teramo K (2015) Obstetric and perinatal outcome in type 1 diabetes patients with diabetic nephropathy during 1988-2011. Diabetologia 58:678-686

35. Yogev Y, Chen R, Ben-Haroush A, Hod M, Bar J (2010) Maternal overweight and pregnancy outcome in women with Type-1 diabetes mellitus and different degrees of nephropathy. J Matern Fetal Neonatal Med: Off J Eur Assoc Perinat Med Fed Asia Oceania Perinat Soc Int Soc Perinat Obstet 23:999-1003

36. Jensen DM, Damm P, Ovesen P et al (2010) Microalbuminuria, preeclampsia, and preterm delivery in pregnant women with type 1 diabetes: results from a nationwide Danish study. Diabetes Care 33:90-94

37. Hiilesmaa V, Suhonen L, Teramo K (2000) Glycaemic control is associated with pre-eclampsia but not with pregnancy-induced hypertension in women with type I diabetes mellitus. Diabetologia 43: 1534-1539

38. Ramsay JE, Ferrell WR, Crawford L, Wallace AM, Greer IA, Sattar N (2002) Maternal obesity is associated with dysregulation of metabolic, vascular, and inflammatory pathways. J Clin Endocrinol Metab 87:4231-4237

39. Jarvie E, Hauguel-de-Mouzon S, Nelson SM, Sattar N, Catalano PM, Freeman DJ (2010) Lipotoxicity in obese pregnancy and its potential role in adverse pregnancy outcome and obesity in the offspring. Clin Sci (Lond) 119:123-129

40. Harmon AC, Cornelius DC, Amaral LM et al (2016) The role of inflammtion in the pathology of preeclampsia. Clin Sci 130:409419

41. Roberts JM, Bodnar LM, Patrick TE, Powers RW (2011) The role of obesity in preeclampsia. Pregnancy Hypertens 1:6-16

42. Sewell MF, Huston-Presley L, Amini SB, Catalano PM (2007) Body mass index: a true indicator of body fat in obese gravidas. J Reprod Med 52:907-911 